\title{
非侵襲超音波診断・治療統合システムにおける結石破砕条件の同定
}

\section{Identification of Stone Destruction Parameters for Non Invasive Ultrasound Theragnostic System}

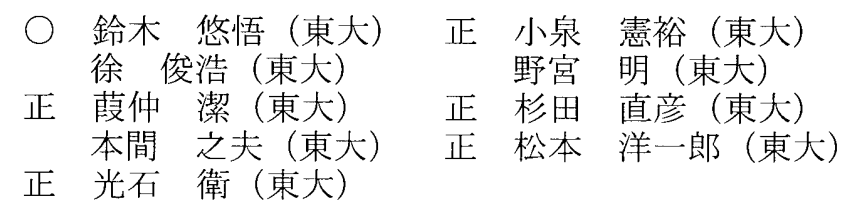

\author{
Yugo SUZUKI, The University of Tokyo, suzuki@nml.t.u-tokyo.ac.jp \\ Norihiro KOIZUMI, The University of Tokyo, \\ Joonho Seo, The University of Tokyo \\ Akira NOMIYA, The University of Tokyo \\ Kiyoshi YOSHINAKA, The University of Tokyo \\ Naohiko SUGITA, The University of Tokyo \\ Yoichiro MATSUMOTO, The University of Tokyo \\ Mamoru MITSUISHI, The University of Tokyo
}

\begin{abstract}
We propose non-invasive ultrasound therapeutic system using visual servoing technology based on real-time ultrasound image processing to compensate the motion of targeting organs. In this paper, we focus on the realization of the effective destruction of kidney stone, and classify the optimized crushing conditions. As a result, Its effectiveness can be validated by the stone tracking experiments conducted according to the optimized stone crushing conditions.
\end{abstract}

Key Words: High-Intensity Focused Ultrasound (HIFU), Non-Invasive Diagnosị and Therapy, Theragnostics

\section{1. はじめに}

強力集束超音波 (High Intensity Focused Ultrasound: HIFU) は超音波を一力所に集束させたものであり，周りの体組 織に損傷を与えることなく患部のみを治療することができる そのため既存の開腹手術低侵襲手術の代替としてきわめて有 望であり，近年，多くの研究報告がなされている[1]。具体的 な治療例として, 超音波の発熱により悪性腫瘍を壊死させる 治療法[2]や，キャビテーション気泡の崩壊圧を利用した結石 破砕術[3]などが挙げられる. HIFU を利用した代表的なシステ ムとしては，JC HIFU sys-tem[4]が挙げられ，さまざまな夕 イプの腫瘍を対象として計 1000 例以上の臨床応用が報告され ている $[5]$.

現在，結石の治療は衝撃波結石破砕法(Extracorporeal Shock Wave Lithotripsy, ESWL) [6]が主流であるが，キャビ テーションによる体組織損傷や破砕片の微細化が困難である ことが問題となっている. キャビテーションの影響はHIFUを 用いることにより微小な領域にのみ抑えることができると考 えられ，EWSLが抱える問題を解決できることから，超音波結
石破砕法の研究が行われている.

超音波結石破砕法では高周波と低周波の 2 種類の周波数の HIFU を用いてキャビテーションの発生と崩壊の制御を行う. 高周波の超音波が結石表面に気泡群を発生させ，低周波の超 音波が気泡群を共振・崩壊させることで結石を破砕する、破 砕の効率にはキャビテーション気泡の挙動が重要であり, 挙 動の観察や照射条件と挙動の関係に関する研究 [3]が行われ ているが，実際の結石の破砕においては破砕効率を定量的に 評価することが難しいため, HIFU の加工能力と照射パラメー 夕との直接的な関係についてはまだ分かっていないところが 多い.

本研究では HIFU の加工能力と照射パラメータとの関係を明 らかにすることを目的として実験を行った。まずは超音波の 加工性能に重要な焦点形状を知ることを目的として, 音圧セ ンサを用いて水中における音圧分布を測定した。次に，結石 ではなく石膏を削ることで照射パラメータと加工形状の関係 を定量的に表し考察した。

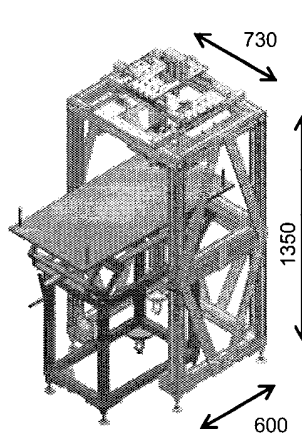

(a) Isometric View

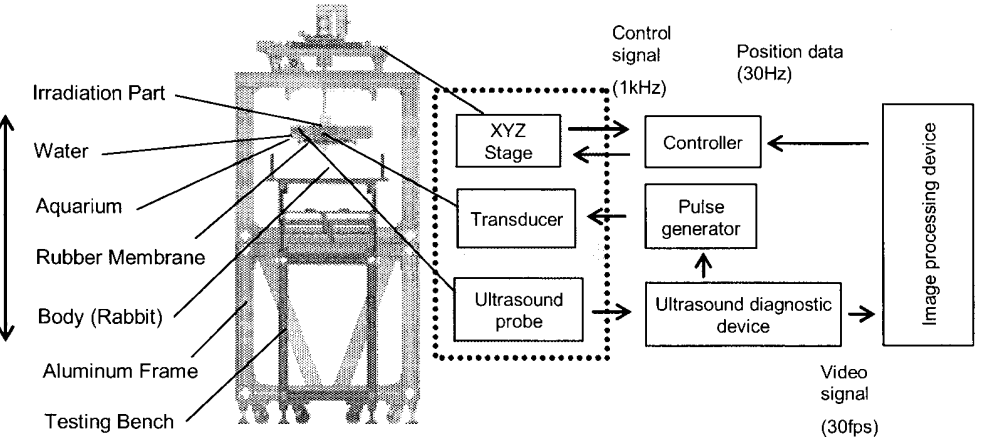

(b) Front View

Fig. 1. Overview and system configuration of the constructed integrated system for non-invasive ultrasound diagnosis and treatment 


\section{2. 非侵襲超音波診断・治療統合システム}

本研究で用いた非侵襲超音波診断・治療統合システムは, 元々，呼吸等により能動的に運動する患部に追従しながら， 超音波を集束させてピンポイントに患部へ照射することによ り, 癌組織や, 結石の破壊を, 患者の皮膚表面を切開寸るこ となく非侵襲かつ低負担で行なおうとするシステムとして開 発されたものである[7]. 非侵襲超音波診断・治療統合システ ムの構成を Fig.1 に示す。まず， 2 方向からの診断用プローブ を用いて超音波診断画像を取得する。つぎに，画像処理装置 を用いて，超音波照射位置と患部の 3 次元位置データを取得 する.制御部では，これらの位置データをもとにXYZ ステー ジを駆動し，超音波照射位置を患部に追従させる。最後に， パルス・ジェネレータおよびトランスデューサを用いて超音 波を照射する。このシステムにおけるトランスデューサは Fig.2 に示寸ように直径 $100 \mathrm{~mm}$ であり, 中心部に超音波プロー ブを取り付けるための直径 $50 \mathrm{~mm}$ の穴が開いている.

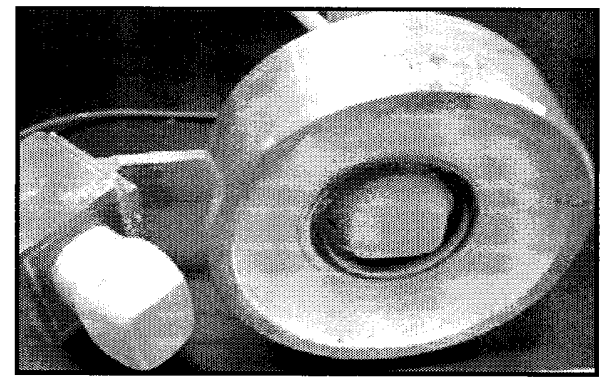

Fig.2 Transducer

\section{3. 焦点形状測定}

超音波の焦点形状が加工に与える影響は大きいが，実際に計 測寸るのは時間が膨大にかかるため，シミュレーションで計 算するのが一般的で，実測では限られた点数しかできないの が現状である．音圧は Fig.3に示すようにニードルハイドロフ オンを使用して測定し, 超音波は現象を単純化するために Fig.4のような高周波のみを照射した．測定範囲は $\mathrm{x}$ 軸方向に $0.5 \mathrm{~mm}, \mathrm{z}$ 軸方向に $1.0 \mathrm{~mm}$ 間隔で， $6 \mathrm{~mm} \times 20 \mathrm{~mm}$ つまり $13 \times$ 21 点の領域を測定した。超音波の照射条件を Table.1に示す. 測定結果を Fig. 5 に示す. 焦点形状は HIFU の照射方向に長 く20Pa 以上の領域が $\mathrm{x}$ 方向に $2 \mathrm{~mm}, \mathrm{z}$ 方向に $15 \mathrm{~mm}$ となった. また，焦点の横にもピークがみられるがこれは同期で照射さ れている超音波同士が強めあったものと考えられる.

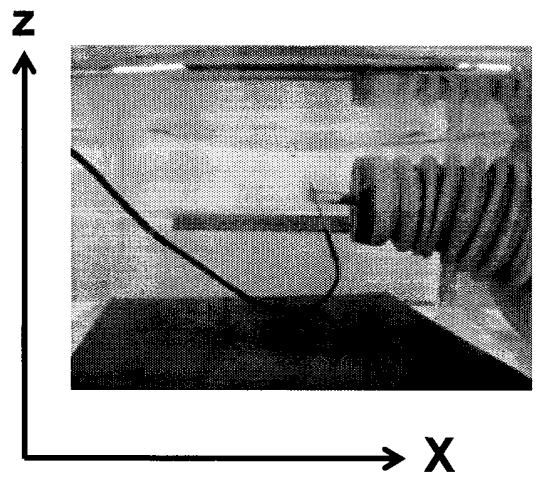

Fig.3 Needle hydrophone

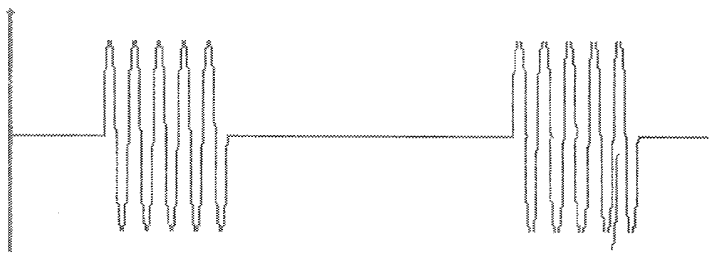

Fig.4 Ultrasound waveform

Table.1 Ultrasound parameters

\begin{tabular}{|l|c|}
\hline 周波数 & $1.66 \mathrm{MHz}$ \\
\hline 振幅(peak-peak) & $2.0 \mathrm{~V}$ \\
\hline サイクル数 & 100,3 \\
\hline パルス繰り返し周波数 & $19 \mathrm{~Hz}$ \\
\hline
\end{tabular}
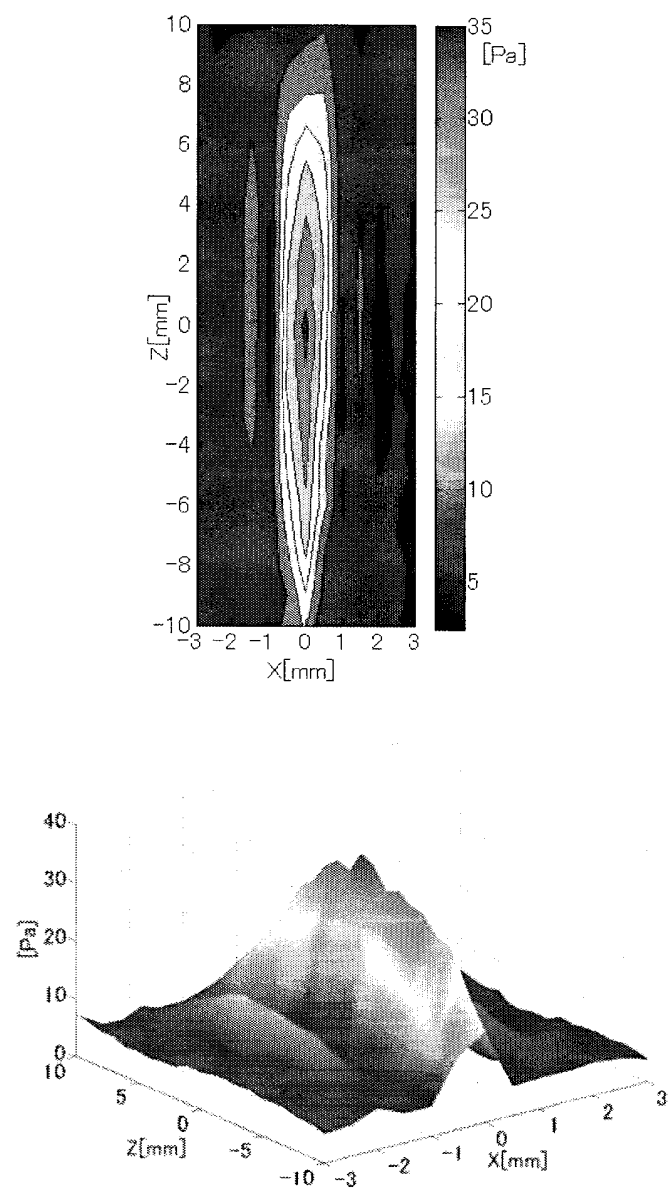

Fig.5 Pressure distribution map

\section{4. 加工実験}

次に，石膏に超音波を照射することにより照射条件と加工 形状に与える影響を考察した。石膏を用いた理由は，結石で は削れたかどうかを定量的に評価することが難しいためであ る。パラメータはキャビテーション気泡に及ぼす影響が大き いと考えられる圧力振幅であり，実験は，（i 高周波部の振幅 を $2 \mathrm{~V}$ に固定し低周波部の振幅を $0 \sim 8 \mathrm{~V}$ の範囲で $1 \mathrm{~V}$ ずつ振つ 
た場合と，(ii ) 低周波部の振幅を6Vに固定し高周波部の振幅 を0〜 4Vの範囲で $0.5 \mathrm{~V}$ ずつを振った場合を行った。超音波は Fig. 6 に示すような 2 種類の周波数を組み合わせたものを照射 し，照射条件は Table.2 に示寸.

( i )の結果を Fig.7，(ii)の結果を Fig.8 に示す. Fig.9 は照射 後の石膏の表面であり，図のように 2 つの穴ができたことか らそれぞれ小穴直径, 大穴直径と名付けた.

小穴直径，大穴直径のうち小穴直径は全ての石膏において 深く削れていたが，大穴は全ての石膏において跡がつく程度 にしか削れていなかった。このため加工効率を判断する上で 重要なのは小穴直径と穴深さであると考えられる。

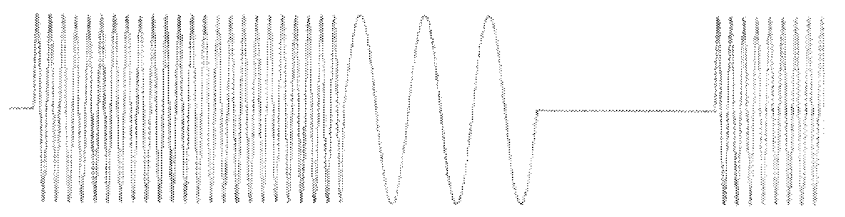

Fig.6 Ultrasound waveform

Table.2 Ultrasound parameters

\begin{tabular}{|l|c|}
\hline 周波数 & $1.66 \mathrm{MHz}, 550 \mathrm{kHz}$ \\
\hline サイクル数 & 100,3 \\
\hline パルス繰り返し周波数 & $19 \mathrm{~Hz}$ \\
\hline 時間 & 15 分 \\
\hline
\end{tabular}

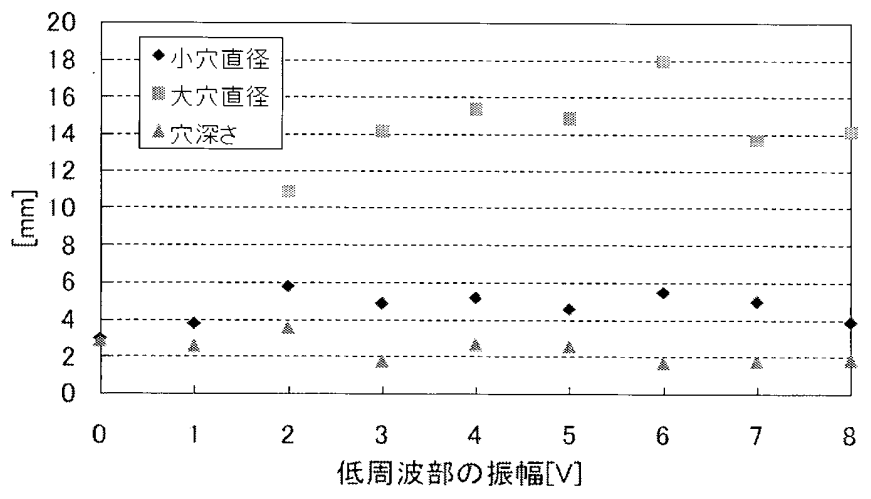

Fig.7 Experiment results (i)

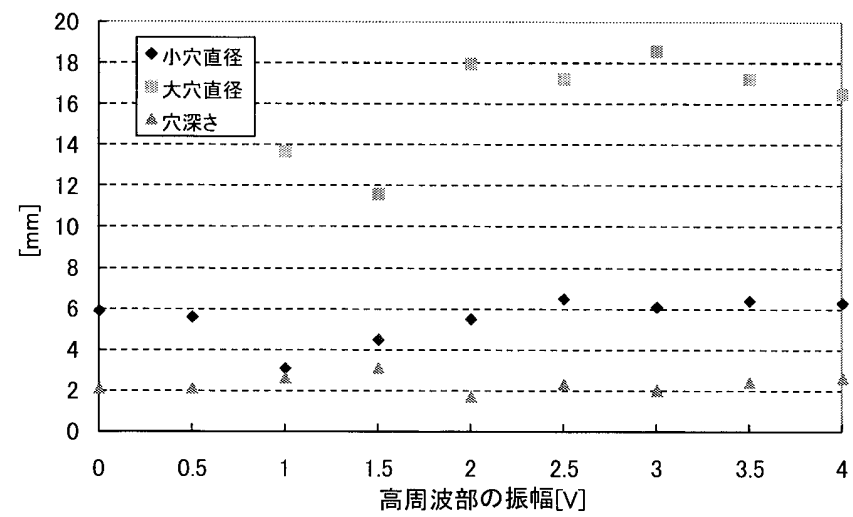

Fig.8 Experiment results (ii)

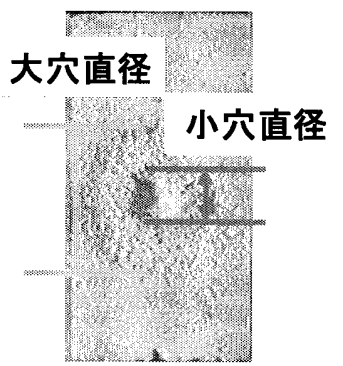

Fig.9 A plaster after experiment

実験 (i)では低周波が $2 V$ 以上において Fig. 7 のような小穴 と大穴が観察され，2V 以下では小穴のみが観察された. Fig. 8 からは，低周波部の圧力振幅が $2 \mathrm{~V}$ 以上の範囲において，圧力 振幅が大きいほうが小穴直径と穴深さが小さくなっており， 加工効率が低下寸ることが分かった。実験 (ii)では高周波が IV 以上に拈いて Fig. 7のような小穴と大穴が観察され，1V以 下では小穴のみが観察された. Fig. 9 からは, 高周波部の圧力 振幅が $1 \mathrm{~V}$ 以上の範囲において，圧力振幅が大きいほうが小穴 直径とが大きくなっており，加工效率が上昇することが分か った．大穴直径が観察されなかった範囲については今回の実 験だけでは分からず，様々な条件で実験するなどしてさらに 考察する必要がある.

\section{5. おわりに}

本稿では, 1 点目として, 超音波結石破砕法の原理と問題点 を述べた， 2 点目として，非侵襲超音波診断・治療統合システ ムについて述べた， 3 点目として，音圧分布測定を行い，結果 と考察を述べた４点目として，石膏を用いた加工実験を行い 結果と考察を述べた.

音圧分布についてはもう少し広い領域において音圧分布の 実測值を測定することが今後の課題である。加工実験において は今回実験したパラメータについてさらに実験を行うことや, 今回実験していないパラメータについて実験することなどが 今後行うことであり, また実験結果とキャビテーションに関す る理論的な部分とのつながりを解明することなどが研究課題 として考えられる.

\section{文献}

[1] J.E.Kennedy, et al.,"High-intensity focused ultra-sound: surgery of the future?," The British Journal of Radiology, Vol.76, pp.590-599, 2003.

[2] Kennedy J E, Haar G T, and Cranston D, High intensity focused ultrasound: surgery for the future?, The British Journal of Radiology, Vol. 76, pp. 590-599, 2003

[3] Ikeda T, Yoshizawa S, Tosaki M, Allen J S, Takagi S, Ohta N, Kitamura T, and Matsumoto Y., Cloud cavitation control for lithotripsy using high intensity forcused ultrasound, Ultrasound Med. Biol., Vol. 32, No. 9, pp. 1383-1397, 2006

[4] G. Tu, T.Y. Qiao, S. He, An experimental study on high-intensity focused ultrasound in the treatment of VX-2 rabbit kidney tumours, Chin. J. Urol. 20 (8) (1999) 456-458.

[5] J.E.Kennedy, et al.,"High-intensity focused ultra-sound for the treatment of liver tumours," Ultrasonics, Vol.42, pp.931-935, 2004.

[6] Eisenmenger $\mathrm{W}$, The mechanism of stone fragmentation in ESWL, Ultrasound in Med. Biol., Vol. 27, No. 5, pp.683-693, 2001

[7] Norihiro Koizumi, Kohei Ota, Deuk-Hee Lee, Shin Yoshizawa, Akira Ito, Yukio Kaneko, Yoichiro Matsumoto, Mamoru Mitsuishi "Feed-forward controller for the integrated non-invasive ultrasound diagnosis and treatment," in Journal of Robotics and Mechatronics, Vol.20, No.1, pp.89-97, 2008. 